\title{
Workplace Accommodations, Job Performance and Job Satisfaction Among Individuals with Sensory Disabilities
}

\author{
Shengli Dong and Amy R. Guerette \\ Florida State University
}

\begin{abstract}
$\mathrm{T}$ his study examined differences between requesters and non-requesters of workplace accommodations in their self-reported job performance and job satisfaction. Participants were 194 individuals with visual and hearing disabilities (females $=67.5 \%$, visual $=53.2 \%$ ) receiving rehabilitation and related services in the US. They completed a survey on their self-reported accommodation requests, job satisfaction and work performance. Chi square and ANOVA tests were used to compare and contrast the differences. Findings suggest participants with requested accommodations have higher levels on job performance and job satisfaction than non-requesters. Individuals who were more likely to request accommodations were associated with higher educational background, moderate disability severity and higher levels of workplace supports from employers and coworkers. They reported higher knowledge levels on Americans with Disabilities Act and accommodation procedures, and higher outcome expectations and self-efficacies in requesting accommodations. Requesting workplace accommodations is an interactive and multifaceted process that involves various biopsychosocial factors. Rehabilitation professionals should help individuals with sensory disabilities from biopsychosoical perspectives to enhance job accommodation and job satisfaction.
\end{abstract}

Keywords: workplace accommodations, sensory impairment, job performance, job satisfaction, biopsychosocial framework

Individuals with sensory disabilities face various social and economic challenges. For instance, the rate of poverty among individuals with sensory disabilities (age 25-61) in the US is $20.7 \%$ compared with only $7.5 \%$ among individuals without disabilities (Harris, Hendershot, \& Stapleton, 2005). The employment rate among individuals with sensory disabilities is much lower than individuals without disabilities, i.e. $58.6 \%$ of individuals with sensory disabilities reported employment in the National Health Interview Survey compared with the $83.3 \%$ of employment rate among individuals without disabilities.

Address for correspondence: Shengli Dong, PhD, Assistant Professor, Psychological and Counseling Services, College of Education, Florida State University. E-mail: sdong3@fsu.edu 


\section{Workplace barriers with sensory disability}

Individuals with hard-of-hearing reported workplace barriers including lack of access to critical interactions, especially in group situations and/or noisy environment (Danermark \& Gellerstedt, 2004; Scherich, 1996). Individuals with visual impairments also experience workplace barriers such as workplace accessibility and mobility, social relationships at work, and performance of essential functions (Rumrill, Schuyler, \& Longden, 1997). These barriers to workplace accessibility and performance negatively affected job satisfaction and job mastery (Rumrill, Roessler, Longden, \& Schuyler, 1998). Unsuccessful resolutions of these barriers could lower the quality of worklife for people with sensory disability as well as trigger legal suites for workplace discrimination charges. According to Bowe, McMahon, Chang, and Louvi (2005), allegations related to workplace accommodations were the second highest type of claim filed with the US Equal Employment Opportunity Commission (EEOC) for individuals with sensory disabilities.

\section{Importance of workplace accommodations}

Workplace accommodations may alleviate some of the challenges to work participation faced by people with disabilities (Hendrick, Batiste, Hirsh, Schartz, \& Blanck, 2005). The Americans with Disabilities Act (ADA) makes employment discrimination illegal, and mandates the provision of workplace accommodations to individuals with disabilities (Americans with Disabilities Act of 1990). Workplace accommodations are defined as 'any change in the work environment (or in the way things are usually done) to help a person with a disability apply for a job, perform the duties of a job, or enjoy the benefits and privileges of employment' (U.S. EEOC, 2011). Accommodations also improve employment, retention and job satisfaction for people with disabilities (Franche, Cullen, Clarke, Irvin, Sinclair, \& Frank, 2005; Hartnett, Stuart, Thurman, Loy, \& Batiste, 2011; Hendricks, Batiste, Hirsh, Schartz, \& Blanck, 2005), employees' and companies' productivity, and employers' satisfaction with accommodations outcomes (Franche et al., 2005; Hartnett et al., 2011).

Despite these benefits and the fact that most accommodation costs are low, and implementation is simple (Friedman, 1993; Hendricks et al., 2005), workplace accommodations have been underutilised (Allen \& Carlson, 2003). Studies continue to report that employers are reluctant to provide them (Balser, 2002; Basas, 2008; Harlan \& Robert, 1998), and employees tend to be reluctant to request accommodations (Allen \& Carlson, 2003; Baldridge \& Veiga, 2001; Balser, 2002).

Considering the underutilisation of workplace accommodations and high number of EEOC legal charges, it is important to examine the biological (disability and demographics), psychological (self-efficacy, outcome expectation, personal affect) and social (work context) characteristics between individuals with sensory disabilities who have requested and received accommodations and those who did not request or receive accommodations. Understanding the impacts of these biopscyhosoical factors on workplace accommodations and outcomes will help develop effective employeeand employer-focused interventions to improve job satisfactions and subsequently yield fewer EEOC charges. 


\section{Goals of the study}

Despite the importance of this research area, little research has been conducted to investigate the characteristics associated with requesters and non-requesters of workplace accommodations, and impacts of workplace accommodation on job performance and satisfaction for individuals with sensory disabilities. Several studies have highlighted the importance of biological (i.e. disability related), psychological (Baldridge and Veiga, 2001; Dong, Oire, MacDonald-Wilson, \& Fabian, 2012; Florey, 1998), and social (Gates, 2000) factors in the accommodation process. Participants who are deaf and hard of hearing reported that accommodations did not meet their workplace needs and were not happy (Scherich, 1996). The above-studies shed light on this research, however they have their limitations: First, no study has specially examined and compared the characteristics of individuals who requested accommodations and those who did not among individuals with sensory disabilities in a comprehensive manner. Second, little research investigated the impact of accommodation on job satisfaction and job performance from employees' perspectives. There is an urgent need to examine the impacts of workplace accommodations on bolstering work productivity and workplace satisfaction for individuals with sensory disabilities (Davila et al., 2009).

The purposes of this study were to compare and contrast the biopsychosocial characteristics between requesters (including received and non-received groups) and non-requesters of workplace accommodations, and examine the impacts of requesting accommodations on self-reported job performance and job satisfaction. This study will answer the following research questions:

1. What are the associations of requesting and receiving workplace accommodations on job performance and job satisfactions among individuals with sensory disabilities?

2. How do differences in biopsychosocial characteristics relate to requesting workplace accommodations with sensory disability?

\section{Method}

\section{Participants and Setting}

Participants in this study were recruited from agencies serving individuals with visual and/or hearing impairments in the US such as Hearing Loss Association of America (HLAA), National Association of the Deaf, Hearing Loss Association of America, Alliance on Aging and Vision Loss, American Association of Visually Impaired Attorneys, Independent Visually Impaired Enterprisers, National Alliance of Blind Students, and American Foundation for the Blind, and so on. The study sample comprised 194 people with sensory disabilities, of whom 161 (83\%) were Caucasian (see Table 1 for participant demographics). In the sample, 102 participants reported being hearing impaired, 116 reported being visual impaired, with 24 participants selfidentified both visually and hearing impaired. The participants reported a high level of educational attainment: $87 \%$ of the participants held a four-year college degree or higher. About $74 \%$ of participants worked full time. 
TABLE 1

Demographic Characteristics of Participants

\begin{tabular}{|c|c|c|c|}
\hline & Variables & $\mathrm{N}$ & Percentage (\%) \\
\hline \multirow[t]{2}{*}{ Gender* } & Female & 131 & 67.5 \\
\hline & Male & 61 & 31.4 \\
\hline \multirow[t]{6}{*}{$\mathrm{Age}^{*}$} & $18-24$ & 5 & 2.6 \\
\hline & $25-34$ & 47 & 24.9 \\
\hline & $35-44$ & 29 & 15.3 \\
\hline & $45-54$ & 61 & 32.3 \\
\hline & $55-64$ & 40 & 21.2 \\
\hline & $>65$ & 7 & 3.7 \\
\hline \multirow[t]{5}{*}{ Race* $^{*}$} & Caucasian & 161 & 83. \\
\hline & African-American & 12 & 6.2 \\
\hline & Asian-American & 6 & 3.1 \\
\hline & Latino/Hispanic & 11 & 5.7 \\
\hline & Native American & 3 & 1.5 \\
\hline \multirow[t]{5}{*}{ Education* } & High school & 20 & 10.7 \\
\hline & 2-year college & 22 & 11.8 \\
\hline & 4 -year college & 81 & 43.3 \\
\hline & Masters & 50 & 26.7 \\
\hline & Doctorate/professional & 14 & 7.5 \\
\hline \multirow[t]{2}{*}{ Work status* } & Working part time & 49 & 26.3 \\
\hline & Working full time & 137 & 73.7 \\
\hline \multirow[t]{4}{*}{ Job level* } & Non-managerial & 105 & 56.1 \\
\hline & Lower-level manager & 29 & 15.5 \\
\hline & Middle-level manager & 38 & 20.3 \\
\hline & Upper-level manager & 15 & 8.0 \\
\hline Disability & Hearing impaired/deaf & 102 & 46.8 \\
\hline Type** & Visual impaired/blind & 116 & 53.2 \\
\hline
\end{tabular}

*N's do not sum to 194 as not all participants answered all demographic questions. **Including 24 participants who identified as dual sensory disabilities.

\section{Procedures}

The participants in this study were part of a large sample of the dissertation study of the first author. The Institutional Review Board at the first author's graduating university approved this study. The first author contacted the agencies mentioned in the prior section that serve individuals with visual and/or hearing impairments, and emailed the web link of the online survey to the directors and asked them to invite participants through their e-newsletters and list-serves. Interested participants followed the links to the web survey, having no direct contact with the researchers, and no personal identity or contact information was collected in the survey. 
Participants who chose to fill out the online survey were asked to read the online consent form prior to taking the survey. Informed consent was implied if participants filled out and submitted the surveys. All collected data was kept in a password protected computer file (electronic copies). All of the surveys were destroyed after the data was entered into a computer database. All data was analysed and reported in a collective manner. No personal information was identifiable.

Once they completed the survey and submitted their responses, participants were given the option to contact researchers to enter a drawing for a gift card, at which time contact information was requested. Forty gift-card drawings ( $\$ 20$ each) were used to enhance recruitment to the study. The contact information was destroyed once the gift certificates were sent out.

Since most of the survey promotion and recruitment was conducted through online notices and websites in multiple branches of these organisations, no response rate was estimated.

\section{Measures}

Participants completed the following measures such as outcome expectation (Baldrdige, 2001; Florey, 1998), self efficacy (Karoly \& Ruehlman, 1995; Rumrill, 1993), affect (PANAS; Watson, Clark, \& Tellegen, 1988). They provided data on their personal demographics, including on disability type, severity and the extent to which disability influenced their work participation. In addition, they provided data on their perception of workplace supports.

\section{Outcome Expectations}

Outcome expectations were assessed through the following domains: anticipated employer compliance for accommodation, accommodation appropriateness, perceived accommodation usefulness, and personal cost (Baldridge, 2001; Florey, 1998). Participants were asked to respond to each of the three items on anticipated employer compliance on a five-point scale ranging from 'Disagree' (1) to 'Agree' (5). The scale demonstrated good internal consistency reliability in Baldrige's study, estimated at 0.97 . The alpha level for this current study was 0.95 .

Florey's (1998) three-item scale on accommodation appropriateness was modified (i.e. replace 'adjustment' with 'accommodation') for consistency with other parts of the survey. Participants were asked to respond to each of the three items on a five-point scale ranging from 'Disagree' (1) to 'Agree' (5). The scale demonstrated good internal consistency reliability, estimated at 0.94 . The alpha level for this current study was 0.96.

Perceived accommodation usefulness was initially a seven-item scale developed by Davis (1989), and later refined into a five-item scale by Baldridge (2001). Three items from Baldridge's scale were used with minor modification (i.e. replacing 'adjustment' with 'accommodation'). Participants were asked to respond to each of the three items on a five-point scale ranging from 'Disagree' (1) to 'Agree' (5). The scale was found to have good internal consistency reliability, estimated at 0.92 in Baldrige's study. The alpha level for this current study was 0.88 .

The seven-item personal cost measure was initially developed by Anderson and Williams (1996). Baldridge (2001) revised the measure slightly. Considering the 
response burden of the participants, three items from Baldridge's study were used with only minor modifications (i.e., replace 'adjustment' with 'accommodation'). Participants were asked to respond to each of the three items on a five-point scale ranging from 'Disagree' (1) to 'Agree' (5). The scale was found to have good internal consistency reliability, estimated at 0.97 in Baldridge's study. The alpha level for this current study was 0.75 .

\section{Self-Efficacy}

In this study, one accommodation domain-specific self-efficacy scale and one goalsetting self-efficacy scale were used. The accommodation domain-specific self-efficacy was developed by Rumrill (1993), and used to assess self-efficacy related to requesting job accommodations. The scale was found to have good internal consistency reliability, estimated at 0.93 in Rumrill's study. The scale in this study was modified slightly (i.e., replacing 'my needs' with 'my accommodation needs'). Considering the response burden of the participants, four items from this scale were used. In addition, to be consistent with other scales in this study, participants were asked to rate their level of confidence in accommodation tasks on a five-point Likert scale 'Not at all confident' (1) to 'Very Confident' (5). The alpha level for this current study was 0.88 .

The work-related goal self efficacy was measured by a modified goal self-efficacy instrument (Karoly \& Ruehlman, 1995), used to assess the degree to which participants feel capable of achieving their most important work-related goal. This scale was modified slightly for consistency with other parts of the survey, and address work domain goals. For the purpose of this study, participants were asked to answer each item by considering important work-related goals they have, and respond to each item on a five-point scale. Karoly and Ruehlman (1995) reported reliability estimates for this scale ranging from 0.80 to 0.87 for health, interpersonal and academic goals. The alpha level for this current study was 0.94 .

\section{Affect}

The Positive and Negative Affect Schedule (PANAS; Watson et al., 1988) is a 20item measure used to assess differences in positive and negative emotions. The scale assesses positive affect (PA), which is defined as the extent to which a person feels enthusiastic, alert and active; and negative affect (NA) which reflects a person's negative emotions, including anger, contempt, distress and guilt. It has also shown strong discriminant and convergent validity, indicating the measure is sufficiently discernable from related constructs such as depression and state anxiety (Watson et al., 1988). In consideration of the practicality of data collection and response burden for the participants, five items from positive affect was chosen. For the purposes of this study, participants were asked to rate how they feel on a five-point scale from 'Not at all' (1) to 'Extremely' (5) when considering asking for job accommodations in the past three months. The alpha level for this current study was 0.87 for positive affect.

\section{Willingness to Request Accommodations}

Intention to request job accommodations were measured by two of the following items developed by Florey (1998): readiness in requesting job accommodations and 
commitment in requesting job accommodations. Participants were asked about their level of readiness and commitment in making accommodation requests in the past three months and assessed on a five-point response scale from 'Not at all ready to ask' to 'Definitely ready to ask', and from 'Not at all committed to ask' and 'Strongly committed to ask'. The reliability of the scale was 0.94 (Florey, 1998). The alpha level for this current study was 0.77 .

\section{Subjective Factors}

Participants' perception of cost, necessity and supervision/involvement from supervisor for the workplace accommodation they requested or considered were assessed using the following questions. 'How necessary was the accommodation(s) in helping you to do your job well? (ranging four categories from 'Not at all necessary' to 'Very necessary'), 'How much do you think the accommodation(s) cost your employer?' (ranging five categories from 'no cost involved' to 'more than \$500'), 'Did the requested accommodations(s) require ongoing and extra supervision or involvement from your supervisor? (ranging four categories from 'Never' to 'Always'). In addition, we use the following questions to assess the participants' knowledge of Americans with Disabilities Act and workplace accommodations. 'Please rate your level of knowledge on the Americans with Disabilities Act when you considered or requested the accommodations (ranging four categories from 'Not at all knowledgeable' to 'Very knowledgeable'), and 'Please rate your level of knowledge on job accommodation procedures and processes in the organisation where you considered or asked for the accommodations (ranging four categories from 'Not at all knowledgeable' to 'Very knowledgeable').

\section{Work Context Factors}

The organisational and social supports for participants were assessed by asking participants to rate their relationships both with their employer/supervisor and coworkers at the workplace where they considered or asked for the accommodations (ranging five categories from 'Very bad' to 'Very good'). Similarly, participants were asked to rate the supportiveness from their employers/supervisor and coworkers (ranging five categories from 'Not at all supportive' to 'Very supportive'). Finally, participants were asked on how did they agree with the following statements 'My company has a disability-friendly environment (i.e. recruiting and employing persons with disabilities' and 'I felt accepted by my coworkers at the workplace where I requested or considered accommodations'. Both the last questions were rated on five categories from 'Strongly disagree' to 'Strongly agree'. The alpha level for this current study was 0.84 .

\section{Job Satisfaction and Job Performance}

Job satisfaction and job performance for participants were assessed by asking participants to rate their job satisfaction with provision of the accommodations (ranging from 'Not at all satisfied' to 'Very satisfied'). In addition, participants were also asked to rate their supervisor/employer satisfaction level with their job performance with the provision of accommodation (ranging five categories from 'Not at all satisfied' to 'Very satisfied'). To assess participants' job performance level, they were asked to rate their 
own and their employers' perception on their job performance (ranging five categories from 'Poor' to 'Excellent'). The alpha level for job satisfaction and job performance of this current study was 0.82 and 0.63 respectively.

\section{Data Analysis}

To answer the research questions in this study, ChiSquare and ANOVA tests were used. ChiSquare testes examined the relationships between accommodation requesting and receiving status (not requested, requested but not received, requested and received) and such categorical variables such as gender, age (18-44 and 44 or older), dual sensory disability (yes/no), working status (full time or part time), race (White or non-white), and job level (management or non-management).

ANOVA tests with post-hoc and t-tests were used to examine the group mean differences in terms of the biopsychosocial factors among participants who did not request accommodation, those who requested but did not receive accommodations and those who requested and received. As per Table 3 for variables used for the analysis. Tukey tests were used in the multiple comparison procedures to control the cumulative Type I error rate. The Tukey tests was chosen since they work well when sample sizes are unequal, and they control for Type I error without the risk of decreasing the power (Napierala, 2012).

\section{Results}

\section{Accommodation Requested or Considered}

Of the accommodations made or considered, assistive technology and assistance by others were the top two categories both the participants who requested the accommodations and participants who considered but did not request the accommodations among individuals with sensory disabilities (see Table 2 for details).

\section{Impacts of Accommodations on Job Satisfaction and Job Performance}

A one-way ANOVA test was used to test for differences on perceptions of accommodations on job performance among three groups (individuals who did not request accommodations, individuals who requested but did not receive accommodations, and individuals who requested and received accommodations). The impact of accommodations on job performance differed significantly across the three groups, $F(2,189)=$ $6.792, p=0.001$, and $F(2,189)=3.169, p=0.045$ for self perception on impacts of accommodation on job performance and assumed employers' perception on impact of accommodation on job performance respectively. Tukey post-hoc comparison indicated that participants who received and requested but did not receive accommodations reported significantly higher $($ Mean $=3.10, \mathrm{SD}=0.692 /$ Mean $=2.95, \mathrm{SD}=$ 0.987 ) on their belief that the accommodation improved their job performance than individuals who did not request $($ Mean $=0.246, \mathrm{SD}=0.948, \mathrm{p}<0.05)$. Similarly, participants who received accommodations reported significantly higher on their assumed employers' belief that the accommodation improved their job performance (Mean $=3.14, \mathrm{SD}=0.780$ ) than individuals who requested but did not received $($ Mean $=2.68, \mathrm{SD}=1.45, \mathrm{p}<0.05)$. 


\section{TABLE 2}

Workplace Accommodations Requested and Not Requested

\begin{tabular}{|c|c|c|c|}
\hline Request Status & Accommodation Type & $\mathrm{N}$ & $\begin{array}{l}\text { Percentage } \\
(\%)^{*}\end{array}$ \\
\hline \multirow{7}{*}{$\begin{array}{l}\text { Subject who requested } \\
\text { accommodations } \\
(N=168)\end{array}$} & Assistive technology & 100 & 59.5 \\
\hline & Assistance by another person & 61 & 36.3 \\
\hline & Flexible Schedule & 31 & 18.4 \\
\hline & $\begin{array}{l}\text { Job restructuring (i.e., change in job } \\
\text { duties) }\end{array}$ & 18 & 10.7 \\
\hline & $\begin{array}{l}\text { Physical alteration to building/office } \\
\text { space }\end{array}$ & 16 & 9.5 \\
\hline & Reassignment to another job & 12 & 7.1 \\
\hline & Telework & 10 & 5.9 \\
\hline \multirow{3}{*}{$\begin{array}{l}\text { Subject who did not } \\
\text { request but } \\
\text { considered }\end{array}$} & Assistance by another person & 11 & 42.3 \\
\hline & Assistive technology & 10 & 38.4 \\
\hline & Flexible Schedule & 8 & 30.7 \\
\hline accommodations & Job restructuring (i. e., change in job & 8 & 30.7 \\
\hline \multirow[t]{4}{*}{$(\mathrm{N}=26)$} & duties) & 8 & 30.7 \\
\hline & Telework & 3 & 11.5 \\
\hline & Reassignment to another job & 3 & 11.5 \\
\hline & $\begin{array}{l}\text { Physical alteration to building/office } \\
\text { space }\end{array}$ & 1 & 3.8 \\
\hline
\end{tabular}

*Percentages add up over $100 \%$, as multiple accommodations can be chosen.

Independent t-tests were used to examine the impacts of accommodation on job satisfaction between individuals who requested accommodations and those did not. Individuals who requested accommodations reported significantly higher levels of work satisfaction (Mean $=3.32, \mathrm{SD}=0.827$ ) than those did not request $($ Mean $=2.35, \mathrm{SD}=1.23, \mathrm{t}=30.198, \mathrm{p}<0.05)$. They also reported higher employer satisfaction (Mean $=3.36, \mathrm{SD}=0.783$ ) than those did not request accommodations $($ Mean $=2.96, \mathrm{SD}=0.859, \mathrm{t}=32.226, \mathrm{p}<0.05$ (see Table 3 for details).

\section{Comparison on Biopsychosoical Characteristics}

Disability and Demographic Factors. Among the disability and demographic related factors, disability severity, level of education and age were found significantly associated with requesting workplace accommodations. Accommodation requesting and/or requesting were more likely with severe disability (Mean $=2.22, \mathrm{SD}=0.69 /$ Mean $=1.98, \mathrm{SD}=0.793)$ than with less severe disability $($ Mean $=1.46, \mathrm{SD}=0.989$, $\mathrm{F}(2,184)=7.184, \mathrm{p}<0.01$, and with higher educational level (Mean $=2.41, \mathrm{SD}$ $=1.186 /$ Mean $=2.11, \mathrm{SD}=0.964)$ rather than lower educational level (Mean = $1.46, \mathrm{SD}=1.029), \mathrm{F}(2,184)=6.861, \mathrm{p}<0.01$. Older individuals were less likely to request accommodations compared with younger individuals $\chi(\mathrm{df}=2)=11.002$, 
TABLE 3

Relationship of Accommodations Requesting with Various Personal and Work Context

\begin{tabular}{|c|c|c|c|c|c|c|c|}
\hline & Request and & & Value & & & & $P-$ \\
\hline Variable & Received Status & $N$ & Range & Mean & Sd. & $F$ & value* \\
\hline \multicolumn{8}{|l|}{ Disability/Demographic Related Factors } \\
\hline \multirow[t]{3}{*}{ Disability Severity } & Not Requested & 26 & & $1.46_{b}$ & .989 & & \\
\hline & Requested But Not Received & 41 & $0-3$ & $2.22_{a}$ & .690 & 7.184 & .001 \\
\hline & Requested and Received & 120 & & $1.98_{a}$ & .793 & & \\
\hline \multirow[t]{3}{*}{ Highest Education Level Completed } & Not Requested & 26 & & $1.46_{b}$ & 1.029 & & \\
\hline & Requested But Not Received & 39 & $0-4$ & $2.41_{\mathrm{a}}$ & 1.186 & 6.861 & .001 \\
\hline & Requested and Received & 122 & & $2.11 \mathrm{a}$ & .964 & & \\
\hline \multicolumn{8}{|l|}{ Psychological Related Factors } \\
\hline \multirow[t]{5}{*}{ Perceptions of WA Necessity } & Not Requested & 26 & & $1.38_{b}$ & .983 & & \\
\hline & Requested But Not Received & 42 & $0-3$ & $2.64 a$ & .485 & 33.437 & .000 \\
\hline & Requested and Received & 122 & & $2.43_{a}$ & .615 & & \\
\hline & Requested But Not Received & 35 & & 3.66 & .591 & & \\
\hline & Requested and Received & 102 & & 3.46 & .685 & & \\
\hline \multirow[t]{3}{*}{ Importance of Accommodations in Reaching Goals } & Not Requested & 20 & & $2.50_{b}$ & 1.192 & & \\
\hline & Requested But Not Received & 35 & $0-4$ & $3.54_{a}$ & .780 & 8.196 & .000 \\
\hline & Requested and Received & 102 & & $3.22_{a}$ & .908 & & \\
\hline \multirow[t]{3}{*}{ Knowledge of ADA } & Not Requested & 26 & & $2.31_{b}$ & 1.050 & & \\
\hline & Requested But Not Received & 42 & $0-4$ & $2.67 \mathrm{ab}$ & .902 & 5.442 & .005 \\
\hline & Requested and Received & 123 & & $2.93_{a}$ & .879 & & \\
\hline \multirow[t]{3}{*}{ Knowledge of Accommodation Procedures } & Not Requested & 26 & & $1.92_{b}$ & 1.129 & & \\
\hline & Requested But Not Received & 42 & $0-4$ & $2.57 \mathrm{a}$ & 1.039 & 6.410 & .002 \\
\hline & Requested and Received & 123 & & $2.71_{a}$ & .981 & & \\
\hline
\end{tabular}


TABLE 3

Continued

\begin{tabular}{|c|c|c|c|c|c|c|c|}
\hline & Request and & & Value & & & & $P-$ \\
\hline Variable & Received Status & $N$ & Range & Mean & Sd. & $F$ & value \\
\hline \multirow[t]{3}{*}{ Negative Affect } & Not Requested & 26 & & $13.08_{a}$ & 6.28 & & \\
\hline & Requested But Not Received & 42 & $5-25$ & $11.40_{a}$ & 4.623 & 8.182 & .000 \\
\hline & Requested and Received & 125 & & $9.18_{b}$ & 4.808 & & \\
\hline \multirow[t]{3}{*}{ Non Personal Cost } & Not Requested & 26 & & $9.12_{b}$ & 2.762 & & \\
\hline & Requested But Not Received & 42 & $3-15$ & $11.14_{a}$ & 3.041 & 6.876 & .001 \\
\hline & Requested and Received & 125 & & $11.58_{\mathrm{a}}$ & 3.165 & & \\
\hline \multirow[t]{3}{*}{ Usefulness } & Not Requested & 26 & & $12.15_{\mathrm{b}}$ & 2.378 & & \\
\hline & Requested But Not Received & 42 & $3-15$ & $13.19_{a b}$ & 2.707 & 5.029 & .007 \\
\hline & Requested and Received & 125 & & $13.69 a$ & 2.104 & & \\
\hline \multirow[t]{3}{*}{ Compliance } & Not Requested & 26 & & $9.81_{b}$ & 3.487 & & \\
\hline & Requested But Not Received & 42 & $3-15$ & $9.12_{b}$ & 4.374 & 30.508 & .000 \\
\hline & Requested and Received & 125 & & $13.15_{a}$ & 2.670 & & \\
\hline \multirow[t]{3}{*}{ Appropriateness } & Not Requested & 26 & & $10.92_{b}$ & 3.019 & & \\
\hline & Requested But Not Received & 42 & $3-15$ & $11.76_{b}$ & 3.413 & 7.393 & .001 \\
\hline & Requested and Received & 125 & & $13.03_{a}$ & 2.652 & & \\
\hline \multirow[t]{3}{*}{ Goal Efficacy } & Not Requested & 26 & & $15.00_{\mathrm{ab}}$ & 3.611 & & \\
\hline & Requested But Not Received & 43 & $4-20$ & $14.84_{b}$ & 2.959 & 4.840 & .009 \\
\hline & Requested and Received & 125 & & $16.5 a$ & 3.539 & & \\
\hline \multirow[t]{3}{*}{ WA Efficacy } & Not Requested & 26 & & $13.04_{b}$ & 3.218 & & \\
\hline & Requested But Not Received & 43 & $4-20$ & $15.16_{a}$ & 4.105 & 11.786 & .000 \\
\hline & Requested and Received & 125 & & $16.48_{a}$ & 3.164 & & \\
\hline
\end{tabular}


TABLE 3

Continued

\begin{tabular}{|c|c|c|c|c|c|c|c|}
\hline & Request and & & Value & & & & $P-$ \\
\hline Variable & Received Status & $\mathrm{N}$ & Range & Mean & Sd. & $F$ & value \\
\hline \multirow[t]{3}{*}{ Willingness to Request } & Not Requested & 26 & & $6.35_{b}$ & 2.171 & & \\
\hline & Requested But Not Received & 43 & $5-10$ & $7.91_{a}$ & 1.862 & 13.558 & .000 \\
\hline & Requested and Received & 125 & & $8.26_{a}$ & 1.541 & & \\
\hline \multicolumn{8}{|l|}{ Social Related Factors } \\
\hline \multirow[t]{3}{*}{ Relationship with Employer } & Not Requested & 25 & & $3.00_{a b}$ & 1.041 & & \\
\hline & Requested But Not Received & 40 & $0-5$ & $2.53_{b}$ & 1.358 & 10.351 & .000 \\
\hline & Requested and Received & 119 & & $3.32 a$ & .769 & & \\
\hline \multirow[t]{3}{*}{ Supportiveness from Employer } & Not Requested & 25 & & $2.7 b_{a}$ & .970 & & \\
\hline & Requested But Not Received & 42 & $0-4$ & $1.71_{b}$ & 1.175 & 34.797 & .000 \\
\hline & Requested and Received & 123 & & $3.17_{a}$ & .903 & & \\
\hline \multirow[t]{3}{*}{ Disability-Friendly Environment } & Not Requested & 25 & & $2.32_{b}$ & 1.069 & & \\
\hline & Requested But Not Received & 42 & $0-4$ & $1.19 c$ & 1.11 & 40.886 & .000 \\
\hline & Requested and Received & 123 & & $2.92_{a}$ & .096 & & \\
\hline \multirow[t]{3}{*}{ Acceptance From Coworkers } & Not Requested & 25 & & $2.48_{b}$ & 1.194 & & \\
\hline & Requested But Not Received & 42 & $0-4$ & $2.26_{b}$ & 1.432 & 13.352 & .000 \\
\hline & Requested and Received & 123 & & $3.16_{a}$ & .862 & & \\
\hline
\end{tabular}




\section{TABLE 3}

Continued

\begin{tabular}{|c|c|c|c|c|c|c|c|}
\hline Variable & $\begin{array}{c}\text { Request and } \\
\text { Received Status }\end{array}$ & $\mathrm{N}$ & $\begin{array}{l}\text { Value } \\
\text { Range }\end{array}$ & Mean & Sd. & $F$ & $\begin{array}{c}P- \\
\text { value* }\end{array}$ \\
\hline \multicolumn{8}{|c|}{ Impacts of RA on Job Satisfaction and Job Performance } \\
\hline \multirow[t]{3}{*}{ Perception on Job Performance } & Not Requested & 26 & & $2.46_{b}$ & .948 & & \\
\hline & Requested But Not Received & 42 & $0-4$ & $2.95_{a}$ & .987 & 6.792 & .001 \\
\hline & Requested and Received & 124 & & $3.10_{a}$ & .692 & & \\
\hline \multirow[t]{3}{*}{ Assumed Employers' Perception on Job Performance } & Not Requested & 24 & & $2.83_{\mathrm{ab}}$ & 1.049 & & \\
\hline & Requested But Not Received & 37 & $0-4$ & $2.68_{b}$ & 1.454 & 3.169 & .045 \\
\hline & Requested and Received & 103 & & $3.14_{a}$ & .780 & & \\
\hline \multirow[t]{2}{*}{ Perception of job satisfaction } & Not Requested & 26 & $0-4$ & 2.35 & 1.231 & 30.198 & .001 \\
\hline & Requested & 117 & & 3.32 & .827 & & \\
\hline \multirow[t]{2}{*}{ Assumed Employers' Perception on job Satisfaction } & Not Requested & 26 & $0-4$ & 2.96 & .859 & 32.226 & .028 \\
\hline & Requested & 106 & & 3.36 & .783 & & \\
\hline
\end{tabular}

*P-value from the overall ANOVA test (All the variables are participants' self-reported perceptions)

Mean scores that do not share subscripts differ at $p<.05$ in the multiple comparisons (Tukey Test).

'WA' stands for workplace accommodations. 


\section{TABLE 4}

Contrast Comparison of Proportions with Accommodation Requesting, Disability, and Work Participation Factors

\begin{tabular}{|c|c|c|c|c|c|c|c|}
\hline & \multirow[b]{2}{*}{ Variables } & \multicolumn{3}{|c|}{$\begin{array}{l}\text { Accommodations Request } \\
\text { and Receive Status }\end{array}$} & \multirow[b]{2}{*}{$d f$} & \multirow[b]{2}{*}{$x^{2}$} & \multirow[b]{2}{*}{$p$ value } \\
\hline & & $\begin{array}{c}\text { Not } \\
\text { Requested } \\
\text { (Mean/ } \\
\text { Percentage) }\end{array}$ & $\begin{array}{l}\text { Requested but } \\
\text { not Received } \\
\text { (Mean/ } \\
\text { Percentage) }\end{array}$ & $\begin{array}{c}\text { Requested } \\
\text { and Received } \\
\text { (Mean/ } \\
\text { Percentage) }\end{array}$ & & & \\
\hline \multirow[t]{2}{*}{ Gender } & Male & $11 / 18.0 \%$ & $9 / 14.8 \%$ & $41 / 67.2 \%$ & & & \\
\hline & Female & $15 / 11.5 \%$ & $33 / 25.2 \%$ & $83 / 63.4 \%$ & 2 & 3.500 & NS \\
\hline \multirow[t]{2}{*}{ Age $^{*}$} & $18-44$ & $9 / 11.1 \%$ & $9 / 11.1 \%_{a}$ & $63 / 77.8 \% a$ & & & \\
\hline & 45/older & $17 / 15.7 \%$ & $31 / 28.7 \% b$ & $60 / 55.6 \% \mathrm{~b}$ & 2 & 11.002 & .004 \\
\hline \multirow{3}{*}{$\begin{array}{l}\text { Dual } \\
\text { Sensory }\end{array}$} & Yes & $4 / 16.7 \%$ & $6 / 25.0 \%$ & $14 / 58.3 \%$ & & & \\
\hline & & & & & & & \\
\hline & No & $22 / 12.9 \%$ & $37 / 21.8 \%$ & $111 / 65.3 \%$ & 2 & .475 & NS \\
\hline \multirow{3}{*}{$\begin{array}{l}\text { Working* } \\
\text { Status }\end{array}$} & FullTime & $15 / 10.9 \% a$ & $31 / 22.6 \%$ & $91 / 66.4 \%$ & & & \\
\hline & & & & & & & \\
\hline & PartTime & $11 / 22.4 \% \mathrm{~b}$ & $8 / 6.3 \%$ & $30 / 61.2 \%$ & 2 & 4.248 & .05 \\
\hline \multirow[t]{2}{*}{ Race } & White & $23 / 14.6 \%$ & $37 / 23.4 \%$ & $98 / 62.0 \%$ & & & \\
\hline & NoWhite & $3 / 9.7 \%$ & $4 / 12.9 \%$ & $24 / 77.4 \%$ & 2 & 2.721 & NS \\
\hline \multirow[t]{2}{*}{ Job Level } & Management & $12 / 14.6 \%$ & $17 / 20.7 \%$ & $53 / 64.6 \%$ & & & \\
\hline & $\begin{array}{l}\text { Non- } \\
\text { management }\end{array}$ & $14 / 13.3 \%$ & $25 / 23.8 \%$ & $66 / 62.9 \%$ & 2 & .273 & NS \\
\hline
\end{tabular}

*Mean scores that do not share subscripts differ at $p<.05$ in $z$-test.

'NS' stands for not significant.

$\mathrm{p}<0.01$. Similarly, participants who worked part time were disproportionally presented in the category of not requesting accommodation compared with those worked full time, $\chi(\mathrm{df}=2)=4.248, \mathrm{p}<0.05$ (see Table 3 and Table 4 for details).

Psychological Factors. Individuals who received accommodations held significantly higher levels on beliefs that their requests were appropriate (Mean $=13.03, \mathrm{SD}=$ 2.652) than those who did not receive (Mean $=11.76, \mathrm{SD}=3.413)$ and those did not request $($ Mean $=10.92, \mathrm{SD}=3.019), \mathrm{F}(2,190)=7.393, \mathrm{p}<0.01$. Individuals who received accommodations reported higher level on beliefs that their employers will comply with their requests (Mean $=13.15, \mathrm{SD}=2.670$ ) than those who did not receive $($ Mean $=9.12, \mathrm{SD}=4.374)$ and those did not request (Mean $=9.81$, $\mathrm{SD}=3.487), \mathrm{F}(2,190)=30.508, \mathrm{p}<0.01$. Those who received accommodations also believed that accommodations were useful for their jobs (Mean $=13.69, \mathrm{SD}=$ $2.104)$ compared with individuals who did not request (Mean $=12.15, \mathrm{SD}=2.378)$, $\mathrm{F}(2,190)=5.029, \mathrm{p}<0.01$. Individuals who did not request accommodations reported a significantly lower level on assumed non-personal cost (Mean $=9.12$, 
$\mathrm{SD}=2.762)$ compared with individuals who requested but did not receive (Mean $=$ $11.14, \mathrm{SD}=3.041)$ and those who received accommodations $($ Mean $=11.58, \mathrm{SD}=$ 3.165), $\mathrm{F}(2,190)=6.876, \mathrm{p}<0.01$.

Self-efficacy mediated requesting for accommodations in that individuals who received accommodations reported a significantly higher level on goal efficacy (Mean = $16.50, \mathrm{SD}=3.539)$ compared with those who requested but did not receive accommodations $($ Mean $=14.84, \mathrm{SD}=2.959), \mathrm{F}(2,191)=4.840, \mathrm{p}<0.01$. Individuals who did not request accommodations reported a significantly lower level on accommodation request efficacy $($ Mean $=13.04, \mathrm{SD}=3.218)$ than individuals who did not receive (Mean $=15.16, \mathrm{SD}=4.105)$ and individuals who received accommodations $($ Mean $=16.48, \mathrm{SD}=3.164), \mathrm{F}(2,191)=11.786, \mathrm{p}<0.01$. In a similar vein, individuals who did not request accommodations reported a significant lower level on willingness to request accommodations (Mean $=6.35, \mathrm{SD}=2.171$ ) than individuals who requested but did not receive (Mean $=7.91, \mathrm{SD}=1,862)$ and those who received accommodations (Mean $=8.26, \mathrm{SD}=1.541), \mathrm{F}(2,191)=13.558$, $\mathrm{p}<0.01$.

Personal affect was associated with requesting accommodations in that a significantly higher negative affect went with not requesting (Mean $=13.08, \mathrm{SD}=6.28)$ or not receiving accommodations (Mean $=1.40, \mathrm{SD}=4.623)$ compared with lower negative affect who received accommodations (Mean $=9.18, \mathrm{SD}=4.808), \mathrm{F}(2,190)=$ 8.182, $\mathrm{p}<0.01$.

Individuals with lower knowledge of Americans with Disabilities Act (ADA) regarding accommodations were less likely to request accommodations (Mean $=2.31$, $\mathrm{SD}=1.05)$ than those with those with higher knowledge of ADA who received accommodations $($ Mean $=2.93, \mathrm{SD}=0.879), \mathrm{F}(2,188)=5.442, \mathrm{p}<0.01$. Similarly, individuals with lower knowledge related to accommodation policies and procedures were less likely to request accommodations (Mean $=1.92, \mathrm{SD}=1.129$ ) than individuals with higher knowledge of accommodation procedures who did not receive accommodations (Mean $=2.57, \mathrm{SD}=1.039)$ and individuals who received accommodations $($ Mean $=2.71, \mathrm{SD}=.981), \mathrm{F}(2,188)=6.410, \mathrm{p}<0.01$. Individuals who perceived the accommodations were less necessary were less likely to request accommodations $($ Mean $=1.38, \mathrm{SD}=0.983)$ than individuals who requested but did not receive accommodations (Mean $=2.64, \mathrm{SD}=0.485)$ and individuals who received accommodations $($ Mean $=2.43, \mathrm{SD}=0.615), \mathrm{F}(2,187)=33.437, \mathrm{p}<0.01$. Individuals who did not request accommodations also reported significantly lower perception of importance of accommodations in reaching work goals (Mean $=2.50, \mathrm{SD}=1.192$ ) than individuals who requested (Mean $=3.54, \mathrm{SD}=0.780$ ) and individuals who received accommodations $($ Mean $=3.22, \mathrm{SD}=0.908), \mathrm{F}(2,154)=8.196, \mathrm{p}<0.01$ (see Table 3 for details).

Work Context Factors. Individuals who reported higher acceptance from their coworkers were more likely to receive accommodations (Mean $=3.16, \mathrm{SD}=0.862$ ) than individuals who did not request $($ Mean $=2.48, \mathrm{SD}=1.194)$ and individuals who did not receive $($ Mean $=2.26, \mathrm{SD}=1.432), \mathrm{F}(2,187)=13.352, \mathrm{p}<0.01$. Individuals who received accommodations reported highest level of satisfaction with the workplace environment $($ Mean $=2.92, \mathrm{SD}=0.096)$ than individuals who did not receive 
accommodations $($ Mean $=1.19, \mathrm{SD}=1.11)$ and individuals who did not request accommodations (Mean $=2.32, \mathrm{SD}=1.069), \mathrm{F}(2,187)=40.986, \mathrm{p}<0.01$. Participants who received accommodations reported a significantly higher level on relationship with employers (Mean $=3.32, \mathrm{SD}=0.769)$ than individuals who did not receive accommodations (Mean $=2.53, \mathrm{SD}=1.358), \mathrm{F}(2,187)=10.351, \mathrm{p}<0.01$. In addition, individuals who did not receive accommodations reported a significantly lower level on perceived employer supportiveness (Mean $=1.71$, SD $=1.175$ ) compared with the individuals who did not request (Mean $=2.76, \mathrm{SD}=0.97)$ and individuals who received accommodations (Mean $=3.17, \mathrm{SD}=0.903), \mathrm{F}(2,187)=34.797, \mathrm{p}<$ 0.01 .

\section{Discussion}

This study showed that the participants' request and use of workplace accommodations and their job satisfaction and performance are closely associated with disability and demographic, psychological and work context factors.

Individuals with more severe disabilities were more likely to request workplace accommodations and were more likely to feel that accommodations were necessary for workplace success. These results may stem from the fact that individuals who have less severe sensory disabilities (such as a mild hearing impairment or low vision) may try to blend in with typical other co-workers instead of requesting accommodations and drawing attention to their disabilities. The reluctance to request accommodations may be related to social stigma and biases associated with sensory disabilities (McMahon et al., 2008). However, these blending strategies may cost these individuals necessary accommodations for successful work participation (Wilton, 2006). For instance, they may be less successful at work from not requesting needed accommodations or not using necessary assistive technology devices (Wilton, 2006). Acceptance of their disability accommodations is essential for a positive self-concept, strong self-esteem, and future successes (Tuttle \& Tuttle, 2004).

Individuals who work part time were less likely to request and receive accommodations. The findings make sense since part time workers may have lower access to organisational resources (Lawrence \& Corwin, 2003). This finding is important because people with disabilities are twice as likely to be placed in part-time jobs compared with individuals without disabilities (Schur, 2003); - hence with lower access to organisation resources. Individuals with higher levels of education were more likely to have requested workplace accommodations. This result might be explained by their knowledge of and skills for requesting accommodations and self-advocacy (Skinner, 2004). For instance, from their college years, individuals with disabilities learned to self-identify and self-request for accommodations. Students with only a high school education might be less familiar with and less willing to self-advocate in this manner, as all accommodations were provided for them in school. Individuals who did not request workplace accommodations reported lower levels of knowledge of the ADA and procedures for requesting accommodations. This might be because the individuals who have less knowledge about the law and process are less likely to recognise the usefulness and necessity of workplace accommodations, and less likely to self-advocate for requesting accommodations in the workplace (Scherich, 1996). 
Older workers were less likely to request accommodations or less likely to receive accommodations compared with younger workers in this study. Previous studies suggest that older workers with various impairments were less likely to use assistive technology in the workplace (Davila et al., 2008; Williams, Sabata, \& Zoina, 2006). These lower requesting and receiving rates may be explained by older workers who attributed their functional employment needs to aging rather than disability (McMullin \& Shuey, 2006). With the aging workforce and a higher prevalence of sensory impairment among older workers (Lee, Gomez-Marin, Lam, \& Zheng, 2005), there is an urgent need for workplace accommodation among this group.

Individuals who requested and received workplace accommodations reported higher levels of employer supportiveness, co-worker supportiveness, and disability friendly environments. They had higher levels of job satisfaction, a key contributor to maintaining successful employment. It is important to note that this group also reported higher levels of positive affect, which may contribute to their increased feelings of supportiveness. According to Fabian, Edelman and Leedy (1993), social support is a significant mediating factor helping people with disabilities to cope with workplace barriers and stressors. Enhance the natural support approach, such as linking people with disabilities to existing workplace supports that are available formally (company sponsored training programmes) or informally (supports for co-workers), is crucial. Individuals who did not request accommodations in the workplace reported higher levels of negative effect. Negative effect included negative emotions such as anger, contempt, distress and guilt (Watson et al., 1988). These feelings may stem from the lower job satisfaction and lower perceived job performance reported by nonrequesters, as discussed below. This group also reported lower levels of belief that their requests for accommodations were appropriate and belief that employers would comply with their requests, thus potentially creating a negative affect towards the workplace.

Individuals who did not request accommodations reported lower levels of job satisfaction than those who requested and/or received accommodations. This finding underscore the significance of workplace accommodations in helping people with disabilities to improve employment and job satisfaction for people with disabilities (Hartnett et al., 2011; Hendricks et al., 2005). Individuals are more likely to request a workplace accommodation if they feel it will have a positive impact on job performance (Baldridge \& Veiga, 2001). It can be assumed that these individuals have had a positive experience with the specific accommodations requested in the past, either in school or prior employment, and thus have a more positive affect towards their requests and usefulness.

\section{Limitations}

This study examined the self-reported accommodation outcomes by employees with sensory disabilities who were able to respond to the research survey online and/or were able to be contacted for this project. The respondents most likely represent people who are either highly engaged and/or dissatisfied with the accommodation process and outcomes. The views of employees who do not have access to online surveys are not represented here. 
The sample in this study was mostly female, relatively highly educated, Caucasian and middle-aged. They may not be fully representative of individuals with sensory disabilities. Findings may not generalise beyond the sample for this study. Further, the use of a self-report survey questionnaire may have resulted in socially desirable responses from some participants; the extent of which is unknown.

\section{Implications for Rehabilitation Practices}

The findings of the study have important implications for the role of rehabilitation professionals working with adults who have sensory impairments. Rehabilitation professionals should be aware workers with sensory disability may not request needed assistive technology as a workplace accommodation by a majority of participants in the study. Even with the accommodations, rehabilitation professionals need to address the extent to which these are used regardless of age or severity of disability.

Rehabilitation professionals need to educate clients regarding their rights to accommodations under the law and familiarise them with various methods for proactively requesting accommodations. Workers with accommodation request self-efficacy are likely to be successful in their roles.

Social supports are key to success and a positive affect in the workplace. Rehabilitation professionals should assist individuals with sensory disabilities to develop communication and social skills that will enable them to expand their social support network at work and in the community.

\section{Future Research}

Future research needs to use qualitative research methods to examine the relationships between accommodation requests and job satisfaction among individuals with sensory disabilities.

In addition, future research should also focus on workplace accommodations for those in whom the process of aging is also disabling. With the aging trend of US workforce and prevalence of sensory disabilities among older workers, it is critical to examine the accommodation process among older workers and impacts of accommodations on their job performance and satisfaction.

\section{Conclusion}

This study showed that disability and demographic, psychological and social support factors are associated with request and use of workplace accommodations. More importantly, requests and uses of workplace accommodations are associated with higher levels on job satisfaction and job performance. Rehabilitation professionals should work with individuals with sensory disabilities in holistic ways in the process of workplace accommodation to enhance the employment rates and job satisfaction.

\section{References}

Allen, S., \& Carlson, G. (2003). To conceal or disclose a disabling condition? A dilemma of employment transition. Journal of Vocational Rehabilitation, 19, 19-27. 
Americans with Disabilities Act of 1990. 1990. P.L. 101-336.

Anderson, S.E., \& Williams, L.J. (1996). Interpersonal, job, and individual factors related to helping processes at work. Journal of Applied Psychology, 81, 282-96.

Baldridge, D.C. (2001). The everyday ADA: The influence of requesters' assessments on decisions to ask for needed accommodation. Dissertation Abstracts International Section A: Humanities and Social Sciences, 62(8-A), 2807.

Baldridge, D.C., \& Veiga, J.F. (2001). Toward a greater understanding of the willingness to request an accommodation: Can requesters' beliefs disable the Americans with Disabilities Act? The Academy of Management Review, 26, 85-99.

Balser, D.B. (2002). Agency in organizational inequality: Organizational behavior and individual perceptions of discrimination. Work and Occupations, 29, 137-165.

Basas, C.G. (2008). Back rooms, board rooms: Reasonable accommodation and resistance under the ADA. Berkeley Journal of Employment Eु Labor Law, 29, 59-116.

Bowe, F.G., McMahon, B.T., Chang, T., \& Louvi, I. (2005). Workplace discrimination, deafness and hearing impairment: The national EEOC ADA research project. Work, 25, 1925.

Caban, A.J., Lee, D.J., Gomez-Marin, O., Lam, B.L., \& Zheng, D.D. (2005). Prevalence of concurrent hearing and visual impairment in US adults: The National Health Interview Survey, 1997-2002. American Journal of Public Health, 95, 1940-1942.

Danermark, B., \& Gellerstedt, L.C. (2004). Psychosocial work environment, hearing impairment, and health. International Journal of Audiology, 43, 383-389.

Davila, E.P., Caban-Martinez, A.J., Muennig, P., Lee, D.J., Fleming, L.E., Ferraro, K.F., ... Christ, S.L. (2009). Sensory impairment among older US workers. American Journal Public Health, 99, 1378-1385.

Davis, F. (1989). Perceived usefulness, perceived ease of use, and user acceptance of information technology. MIS Quarterly, 13, 319-340.

Dong, S.L., Oire, S., MacDonald-Wilson, K., \& Fabian, E. A comparison of perceptions of factors in the job accommodation process among employees with disabilities, employers, and service providers [published online ahead of print December 10, 2012]. Rehabilitation Counseling Bulletin, DOI: $10.1177 / 0034355212468618$

Fabian, E.S., Edelman, A., \& Leedy, M. (1993). Linking workers with severe disabilities to social supports in the workplace: Strategies for addressing barriers. The Journal of Rehabilitation, 59, 29-34.

Florey, A.T. (1998). Decisions to make an accommodation request: Theory and evidence from the perspective of employees with disabilities. Unpublished doctoral dissertation, University of Texas at Arlington. Dissertation \& Theses: AAT:9921872.

Franche, R.L., Cullen, K., Clarke, J., Irvin, E., Sinclair, S., \& Frank, J. (2005). Workplace-based return-to-work interventions: A systematic review of the quantitative literature. Journal of Occupational Rehabilitation, 15, 607-631.

Friedman, S. (1993). Accommodation Issues in the work place for people with disabilities: A needs assessment in an educational setting. Disability, Handicap 63 Society, 8, 3-23.

Gates, L.B. (2000). Workplace accommodation as a social process. Journal of Occupational Rehabilitation, 10, 85-98.

Harlan, S.L., \& Robert, P.M. (1998). The social construction of disability in organizations: Why employers resist reasonable accommodation. Work and Occupations, 25, 397-435.

Harris, B.H., Hendershot, G., \& Stapleton, D.C. (2005). A guide to disability statistics from the National Health Interview Survey. Rehabilitation Research and Training Center on Disability Demographics and Statistics. Cornell University, Ithaca, NY. Retrieved from http://digitalcommons.ilr.cornell.edu/edicollect/186/. 
Hartnett, H.P., Stuart, H., Thurman, H., Loy, B., \& Batiste, L.C. (2011). Employers' perceptions of the benefits of workplace accommodations: Reasons to hire, retain, and promote people with disabilities. Journal of Vocational Rehabilitation, 34, 7-23.

Hendricks, D.J., Batiste, L., Hirsh, A., Schartz, H., \& Blanck, P. (2005). Cost and effectiveness of accommodations in the workplace: Preliminary results of a nationwide study. Disability Studies Quarterly, 25(4). Retrieved December, 18, 2012, from http://www.dsq-sds.org/article/view/623/800

Karoly, P., \& Ruehlman, L.S. (1995). Goal cognition and its clinical implications: Development and preliminary validation of four motivational assessment instruments. Assessment, 2, 113-129.

Lawrence, T.B., \& Corwin, V. (2003). Being there: The acceptance and marginalization of part-time professional employees. Journal of Organizational Behavior, 24, 923-943. doi: 10.1002/job.229

McMahon, B.T., Roessler, R., Rumrill, P.D., Hurley, J.E., West, S.L., Chan, F., \& Carlson, L. (2008). Hiring discrimination against people with disabilities under the ADA: Characteristics of charging parties. Journal of Occupational Rehabilitation, 18, 122-132.

McMullin, J.A., \& Shuey, K.M. (2006). Ageing, disability, and workplace accommodations. Ageing and Society, 26, 831-847.

Napierala, M. (2012). What is the Bonferroni correction? Retrieved Dec. 28, 2012 from http://www. aaos.org/news/aaosnow/apr12/research7.asp

Rumrill, P.D. (1993). Increasing the frequency of accommodation requests among persons with multiple sclerosis: A demonstration of the Progressive Request Model. ProQuest Information \& Learning, US. AAT 9434924.

Rumrill, P.D. (1999). Effects of a social competence training program on accommodation request activity, situational self-efficacy, and Americans with disabilities act knowledge among employed people with visual impairments and blindness. Journal of Vocational Rehabilitation, 12, 25-31.

Rumrill, P.D., Roessler, R., Longden, J., \& Schuyler, B. (1998). Situational assessment of the accommodation needs of employees with visual impairments and blindness. Journal of Visual Impairment and Blindness, 92, 42-54.

Rumrill, P.D., Schuyler, B., \& Longden, J. (1997). Profiles of on-the-job accommodations needed by professional employees who are blind. Journal of Visual Impairment and Blindness, 91, 66-76.

Schartz, H.A., Hendricks, D.J., \& Blanck, P. (2006). Workplace accommodations: Evidence-based outcomes. Work: A Journal of Prevention, Assessment and Rehabilitation, 27, 345-354.

Scherich, D.L. (1996). Job accommodations in the workplace for persons who are deaf or hard of hearing: Current Practices and Recommendations. Journal of Rehabilitation, 62, 27-35.

Schur, L.A. (2003). Barriers or opportunities? The causes of contingent and part-time work among people with disabilities. Industrial Relations, 42, 589-622.

Skinner, M.E. (2004). College students with learning disabilities speak out: What it takes to be successful in postsecondary education, Journal of Postsecondary Education and Disabilities, 17, 91104.

Tuttle, D.W. \& Tuttle, N.R. (2004). Self-esteem and adjusting with blindness: The process of responding to life's demands. Springfield, IL: Charles C Thomas.

U.S. Equal Employment Opportunity Commission (2011). Enforcement and litigation statistics. Retrieved December 18, 2012, from http://www.eeoc.gov/eeoc/statistics/enforcement/all.cfm

Watson, D., Clark, L.A., \& Tellegen, A. (1988). Development and validation of brief measures of positive and negative affect: The PANAS scales. Journal of Personality and Social Psychology, 54, 1063-1070.

Williams, M., Sabata, D., \& Zolna, J. (2006). User needs evaluation of workplace accommodations. Work, 27, 355-362.

Wilton, R.D. (2006). Disability disclosure in the workplace. Just Labour, 8, 24-39. 